\title{
Age at maturation has sex- and temperature-specific effects on telomere length in a fish
}

\section{Noreikiene, Kristina}

2017-08

Noreikiene , K , Kuparinen , A \& Merilae , J 2017 , ' Age at maturation has sex- and temperature-specific effects on telomere length in a fish ', Oecologia, vol. 184 , no. 4 , pp.

767-777 . https://doi.org/10.1007/s00442-017-3913-5

http://hdl.handle.net/10138/308064

https://doi.org/10.1007/s00442-017-3913-5

unspecified

acceptedVersion

Downloaded from Helda, University of Helsinki institutional repository.

This is an electronic reprint of the original article.

This reprint may differ from the original in pagination and typographic detail.

Please cite the original version. 
$4 \quad$ Kristina Noreikiene ${ }^{1}$, Anna Kuparinen ${ }^{2}$, Juha Merilä ${ }^{1}$

$6{ }^{1}$ Ecological Genetics Research Unit, Department of Biosciences, University of Helsinki, PO Box 65,

$7 \quad$ FI-00014, Helsinki, Finland

$8{ }^{2}$ Department of Biological and Environmental Science, University of Jyväskylä, PO Box 35, FI-40014, 9 Jyväskylä, Finland

10

11 Corresponding author: Kristina Noreikiene (kriste.noreikiene@gmail.com)

12 Running head: Stickleback Telomeres

13 Author Contributions: KN and JM conceived the idea, $\mathrm{KN}$ and $\mathrm{AK}$ designed the experiment, collected

14 the data and performed statistical analyses, $\mathrm{KN}$ and JM wrote the manuscript, AK provided editorial 15 advice. 
Telomeres are highly conserved nucleoprotein structures which protect genome integrity. The length of telomeres is influenced by both genetic and environmental factors, but relatively little is known about how different hereditary and environmental factors interact in determining telomere length. We manipulated growth rates and timing of maturation by exposing full-sib nine-spined sticklebacks (Pungitius pungitius) to two different temperature treatments and quantified the effects of temperature treatments, sex, timing of maturation, growth rate and family (genetic influences) on telomere length. We did not find the overall effect of temperature treatment on the relative telomere length. However, we found that variation in telomere length was related to timing of maturation in a sex- and temperature-dependent manner. Telomere length was negatively related to age at maturation in elevated temperature and early maturing males and females differed in teleomere length. Variation in growth rate did not explain any variation in telomere length. The broad sense heritability $\left(h^{2}\right)$ of telomere length was estimated at $h^{2}=0.31-0.47$, suggesting predominance of environmental over genetic determinants of telomere length variability. This study provides the first evidence that age at maturation together with factors associated with it are influencing telomere length in an ectotherm. Future studies are encouraged to identify the extent to which these results can be replicated in other ectotherms.

Keywords: aging, heritability, Pungitius pungitius, telomere, temperature 
Telomeres are nucleoprotein structures whose main function is to protect genome integrity (Blackburn 2000). Telomeres shorten with every cell division which eventually leads to cellular senescence and various associated pathologies (Blasco 2005). The process of telomere attrition can be accelerated by an array of stressors, and thus an individual's telomere length may be indicative of its exposure to stress and/or its stress resistance (von Zglinicki 2002; Epel et al. 2004; Mizutani et al. 2013). Unsurprisingly, individual variation in telomere length has been linked to variation in various phenotypic attributes, including survival probability (Bakaysa et al. 2007; Monaghan 2010; Heidinger et al. 2012; Angelier et al. 2013). While telomere shortening can be to some extent restored by telomerase enzyme, the process of telomere erosion is usually faster than their elongation (Barrett and Richardson 2011). Furthermore, the process of telomere restoration may be costly either due to elevated risk of pathologies or because of diversion of resources which could otherwise be allocated to other vital life-history functions such as reproduction (Campisi 2005; Monaghan and Haussmann 2006). In fact, when extrinsic mortality is high, investments into the costly maintenance of telomere length maybe wasteful (i.e. "disposable soma theory"; Kirkwood 1977; Kirkwood and Rose 1991). Therefore, whether the benefits of telomere length restoration offset its costs may be highly context dependent, may differ among sexes and among individuals who have experienced different growth histories.

Sex is one of the most important drivers of intraspecific life-history variation (Rice 1984; Slatkin 1984), and telomere length has been repeatedly found to differ between sexes mirroring sex-specific differences in the lifespan (Barrett and Richardson 2011). While the proximate causes for this remains unclear, it is conceivable that sex differences in life histories may also drive variation in telomere 60 dynamics. This possibility is especially interesting in case of sexually dimorphic species in which the 
two sexes may often differ markedly in optimal values of important life history traits (Roff 1993). For example, the optimal age at maturation may be very different for males and females. In ectotherms, such as fish, early maturation is associated with a smaller size, which especially in case of females translates to reduced fecundity (Roff 1993; Shimada et al. 2011), whereas male reproductive success is not, or only weakly so, affected by age at maturation (Adams and Huntingford 1997; Uusi-Heikkilä et al. 2011). Furthermore, experimental studies modulating growth conditions found that high growth rate is associated with early maturation (Kuparinen et al. 2011) and reduced longevity (Lee et al. 2013). Therefore, individuals and sexes with different maturation schedules likely differ in their investment into different life-history traits. Consequently, studies of sex-bias in telomere shortening in species with sex-specific differences in life-history strategies can be particularly rewarding (Barrett and Richardson 2011). However, up to date, only a limited number of studies have studied sex differences in telomere shortening in species where the sexes differ conspicuously in their life histories (Foote et al. 2010; Gopalakrishnan et al. 2013; Rollings et al. 2014; Gao and Munch 2015; Peterson et al. 2015).

As most other quantitative traits, variation in telomere length is known to be influenced both by environmental and genetic factors (Broer et al. 2013; Asghar et al. 2015). Most of what is known about heritability of telomere length comes from human studies where it ranges from a moderate $36 \%$ to as high as 90\% (Bischoff et al. 2005; Baird 2008; Broer et al. 2013). Since traits closely related to fitness are expected to have low heritability (Price and Schluter 1991; Houle 1992; Merilä and Sheldon 1999), the high heritability recovered in human studies could indicate that variation in telomere length is not closely associated with variation in fitness, or that the heritabilities have been overestimated for a reason or another. Evolutionarily more informative insights on the genetic basis of telomere length should be obtainable from studies of non-model organisms (Kappei and Londoño-Vallejo 2008; Monaghan 2010), and such information has been accumulating recently (Horn et al. 2011; Olsson et al. 
2011; Voillemot et al. 2012; Reichert et al. 2015; Asghar et al. 2015; Atema et al. 2015; Becker et al. 2015). However, most of these studies have been conducted with endothermic birds, and to best of our knowledge, only one study has focused on inheritance of telomere length variation in ectothermic vertebrate (Olsson et al. 2011). However, the study of Olsson et al. (2011) is problematic in the sense that it utilized parent-offspring regressions for heritability estimation, in spite of the fact that one of the critical assumptions underlying the usage of this approach is that the comparable trait is measured in parents and offspring. Clearly, if telomeres of parents and offspring are not quantified at the same age and telomere length changes with age, parent-offspring regression may give biased estimates of heritability.

The aim of this study was to assess whether variation in growth rate and age at maturation were associated with variation in telomere length in nine-spined sticklebacks (Pungitius pungitius), and whether these associations were sex-specific. We predicted that i) variation in telomere length will be negatively associated with variation in growth rate, and that ii) mature individuals will have shorter telomeres than immature individuals. The latter may be expected either because of the slower growth, and thus also lower cell division rate, of immature individuals and/or the fact that maturation itself is energetically costly. We do not exclude a possibility that if the trade-off between growth and telomere length arises due to competition for energy and resources it may be infact masked by resource acquisition capacities of individuals. Also, because female maturation on average requires more resources than male maturation (Hayward and Gillooly 2011), we expected that iii) mature females would have shorter telomeres than mature males.

In order to test these predictions, we used data from an experiment where growth rate and timing of maturation were manipulated by exposing individually reared full-sib individuals from the same ninespined stickleback families to two ecologically relevant temperatures (Kuparinen et al. 2011). In 
107 addition, leveraging the relatively large set of full-sib families in the data, we evaluated the relative 108 importance of genetic $v s$ environmental influences (i.e. heritability) in determining variation in 109 telomere length.

\section{MATERIAL AND METHODS}

\section{Fish sampling and rearing}

112 Adult nine-spined sticklebacks were caught with seine nets in 2008 in the Baltic Sea $\left(60^{\circ} 10^{\prime} \mathrm{N} ; 25^{\circ} 00^{\prime}\right.$ E) and transported to laboratory facilities at the University of Helsinki (Finland). Nine full-sib families were created by artificial fertilization as described in (Kuparinen et al. 2011). Fertilized eggs were incubated at $17^{\circ} \mathrm{C}$ and fry were photographed within few hours after hatching to measure hatching size. Shortly after hatching, individuals $(N=400)$ were randomly assigned to one of the two temperature treatments $\left(14^{\circ} \mathrm{C}\right.$ and $\left.17^{\circ} \mathrm{C}\right)$ and two replicates per each family and each treatment so that families were equally represented. Fish were reared individually in $1.4 \mathrm{~L}$ tanks which were separated by opaque plastic sheets. Tanks were arranged in four racks (Allentown Zebrafish Rack System, Aquaneering, San

Diego, USA) housing 100 individuals per rack. Each rack had a separate water circulation system where water was filtered by physical, chemical, biological and UV filters. Light conditions during the entire experiment were set to 24 hour light to mimic high-latitude summer conditions, as well as to enhance growth and development. Individuals were initially fed with live Artemia, but gradually food was changed to Chironomidae larvae. When individuals were 17 days old, weekly size measurements were initiated to follow individual growth trajectories. These size measurements continued until the fish were 15 weeks old (i.e. until 115 days of age) and were obtained by taking a digital photograph

127 from which body length (from the tip of the nose to the end of the tail base) was measured using a 128 software TpsDig 1.4 (Rohlf 2002). 
129 Age at maturation was closely monitored during the entire duration of the experiment. Upon their 130 maturation, male nine-spined sticklebacks develop distinctive nuptial coloration, and were thus

131

132 133 considered mature when first signs of such coloration were observed. Females in this species do not change their coloration visibly when mature, and thus, their maturation was monitored by observing their reproductive status by gently squeezing visually gravid females (twice a day) so as to see if eggs were ready to be released. Mainly due to mortality in early growth stages a substantial proportion (34.75\% or 139 individuals out of 400 ) of individuals were lost. The experiment was terminated when the fish were122 days old and when approximately half of the remaining individuals had matured $(N$ [matured individuals/total number of individuals alive] $=109 / 261)$. Individuals were euthanized with an overdose of MS-222 (tricainemethanesulfonate) and their sex was confirmed or identified (in case of immature individuals) by visual examination of the gonads. Brains were dissected out and stored at $80^{\circ} \mathrm{C}$ until further analyses.

\section{Telomere assay}

Telomere length was determined as the ratio between the amount of telomeric repeats and that of a reference sequence by using quantitative polymerase chain reaction (qPCR; Cawthon 2002). Quantified this way, the relative telomere length (RTL) corresponds to an average telomere length across all chromosomes (Cawthon 2002). This approach to quantify telomere length has been successfully applied in many ecological studies (e.g., Olsson et al. 2011; Heidinger et al. 2012; Plot et al. 2012). The known shortcoming of this method is that if present, qPCR amplifies also interstitial telomeric repeats generating noise for inter-individual comparisons (Foote et al. 2013; Nussey et al. 2014). However, interstitial telomeric repeats have not been detected in nine-spined sticklebacks (Ocalewicz et al. 2011). Telomeric repeats were amplified using universal primers developed by Cawthon (2002): 
152

153

154

155

156

157

158

159

160

161

162

163

164

165

166

167

168

169

170

171

172

173

174

175

Tellb: CGGTTTGTTTGGGTTTGGGTTTGGGTTTGGGTTTGGGTT;

Tel2b: GGCTTGCCTTACCCTTACCCTTACCCTTACCCTTACCCT.

The zinc finger protein 1 gene (zicl) was used as a reference sequence. A partial sequence of zic 1 from Pungitius pungitus was obtained from GenBank (Accession Number:AB445219) and primers amplifying a fragment of this gene were designed using Primer 3 software (Untergasser et al. 2012): PuZic1Fw.: CAACAGGCGAAGTCACAGAG, PuZic1Rev.: CGTGGGAGCTGTGGTTTATT.

For the telomere assay, genomic DNA was extracted from brain tissue using QIAamp Fast DNA Tissue kit (QIAGEN) following manufacturer's instructions. The integrity and purity of the extracted DNA was checked by agarose gel electrophoresis and NanoDrop 2000 (ThermoFisher), respectively. Only visually intact samples with a $\mathrm{A}_{260 / 280}$ ratio higher than $1.7($ mean $\pm \mathrm{SD}=1.85 \pm 0.11)$ were accepted for further analyses. The qPCR reactions were run separately for telomere and reference sequence amplification in a Bio-Rad X1000 real time thermal cycler (BIO-RAD) in 384-well microplates (BIORAD). Each reaction mix included iTaq ${ }^{\mathrm{TM}}$ DNA polymerase, $\mathrm{dNTPs}, \mathrm{MgCl}_{2}$ and fluorescein-SYBR found in $\mathrm{iQ}^{\mathrm{TM}} \mathrm{SYBR}{ }^{\circledR}$ Green $\mathrm{qPCR}$ mix (BIO-RAD), plus primers and 5ng of DNA template. For telomere reactions $100 \mathrm{nM}$ ofTel $1 \mathrm{~b}$ and $300 \mathrm{nM}$ of Tel2b were used, while for $z i c 1$ (reference sequence) $200 \mathrm{nM}$ for both forward and reverse primers were used. All plates included serial doubling dilutions (from $1.25 \mathrm{ng} /$ well to $20 \mathrm{ng} /$ well) of a standard sample, which was made by pooling equal quantities of DNA from five randomly picked individuals. Each plate also included one extra standard sample and a no-template control where DNA volume was substituted with water. All reactions were carried out in triplicate. Individuals were randomly distributed in plates so that all families were proportionally represented on each of the reaction plate. The qPCR thermal cycling protocol for telomere fragment amplification started with an initial denaturation step at $95^{\circ} \mathrm{C}$ for $5 \mathrm{~min}$ followed by 21 cycle of $95^{\circ} \mathrm{C}$ for $30 \mathrm{~s}, 55^{\circ} \mathrm{C}$ for $15 \mathrm{~s}$ and $72^{\circ} \mathrm{C}$ for $30 \mathrm{~s}$. Conditions for $z i c 1$ fragment amplification were as follows: 
$95^{\circ} \mathrm{C}$ for $5 \mathrm{~min}$, and 40 cycles of $95^{\circ} \mathrm{C}$ for $20 \mathrm{~s}, 59^{\circ} \mathrm{C}$ for $30 \mathrm{~s}$ and $72^{\circ} \mathrm{C}$ for $30 \mathrm{~s}$. As the final stage of

177 both protocols melt-curves were generated by slowly $\left(0.1^{\circ} \mathrm{C} / \mathrm{s}\right)$ increasing temperature from 70 to $95^{\circ} \mathrm{C}$.

178 LinRegPCR software was used to determine amplicon specific window of linearity, Cq (threshold cycle

179 when amplification signal crosses the background level) and individual well efficiencies (Ramakers et

180 al. 2003). Plates were standardized for the between plate variation using GenEx 6 software (MultiD,

181 Göteborg). Coefficients of variation (CV) between replicates of the same sample were calculated in

182 percents, and replicates with $\mathrm{CV}>5 \%$ were excluded (2 out of 660 values $[0.3 \%]$ for $z i c 1$ reactions, and 9 values out of 660 [1.36\%] for telomeres). Resulting mean within replicate repeatability calculated as intraclass correlation coefficient (ICC) and CV were high both for $z i c 1\left(\mathrm{ICC}_{\mathrm{zicl}}=0.90, \mathrm{CI}[0.88\right.$ 0.92], $\left.\mathrm{CV}_{\text {zicl }}=0.71 \%\right)$ and telomere primer reactions $\left(\mathrm{ICC}_{\mathrm{TL}}=0.87, \mathrm{CI}[0.83-0.89], \mathrm{CV}_{\mathrm{TL}}=1.73 \%\right)$. Finally, relative telomere length (RTL) was calculated for 213 samples using delta CT method as:

where $C_{t}-$ critical cycle for TL and reference gene (zicl) respectively. To account for potential biases caused by measurement error we have also calculated all combinations of RTL using three replicates of telomere and zic $1 \mathrm{Cq}$ values. Intra-individual repeatability of telomere length calculated in this way was significant (ICC $=0.68, \mathrm{CI}[0.64-0.72])$. Mean estimated RTL-value was $1.10( \pm 0.44 \mathrm{SD}$, range [0.253.86]). We have also used a more common approach of calculating mean values of the replicate $\mathrm{Cq}$ values and thus obtaining only one RTL estimate per individual. Mean estimated RTL-value using this approach was $1.16( \pm 0.46 \mathrm{SD}$, range [0.47-2.43]). One sample more than three standard deviations away from the mean was removed as an outlier. 
198 Individual growth curve parameters were obtained using the von Bertalanffy growth curve equation 199 (von Bertalanffy 1938) and fitting the equation with body size measurements at given age $(l)$ through non-linear least-squares regression (2):

$201 \quad l(t)=L_{\infty}-\left(L_{\infty}-L_{0}\right) e^{-k t}$

202 yielding three measures portraying individual growth: $\mathrm{k}$ - the intrinsic growth coefficient; $\mathrm{L}_{0}-$ size at $203 \mathrm{t}=0$ and $\mathrm{L}_{\infty}$-asymptotic length (Kuparinen et al. 2011). The von Bertalanffy equation described the data 204 very well with the mean goodness of fit estimate of $0.99( \pm 0.004 \mathrm{SD})$. Since growth coefficient and asymptotic size were highly correlated $\left(r_{p}=0.76, P<0.01\right)$ only asymptotic length $\left(\mathrm{L}_{\infty}\right)$ was included in further statistical analyses. Age at maturation is not a growth curve parameter while it is still proportional to asymptotic size $\left(r_{p}=0.53, P<0.01\right)$.

In order to test whether telomere length is associated with growth and maturation in a sex specific manner, we constructed a linear mixed effect (LME) model in which RTL was the response variable, and the fixed explanatory variables were sex, maturation status (matured or unmatured), asymptotic size $\left(\mathrm{L}_{\infty}\right)$ and temperature treatment. Initial models included two-way interactions between these main explanatory variables. We also included hatching size as covariate to control for possible differences in in ovo conditions, which may affect telomere length. Family identity was included as a random factor and the model was fitted with maximum likelihood. Model selection progressed in a step-wise manner by performing likelihood ratio test and excluding non-significant terms from the model (Table1).

As the second analysis step, we constructed an identical model to the one described above, with the difference that the binary maturation status was substituted with a continuous age at maturation (Table 2). Since only 109 out of the 261 surviving individuals reached maturity before the end of the experiment, the sample size in this analysis was substantially lower than in the former. The initial model was reduced using the backward step-wise elimination procedure as described above. Residuals 
221 of the final model adhered to the assumption of normality and variance inflation factors (VIF) were

222 lower than 2.2 for all variables included in the model (Dormann et al. 2013). In all analyses, telomere

223 length was log-transformed before analyses to assure normal distribution of residuals.

224

225

Heritability of telomere length

226 To estimate broad sense heritability $\left(h^{2}\right)$ of telomere length, we used an animal model approach as 227 implemented in the MCMCglmm package in R (Hadfield 2010). Four MCMCglmm models were run 228 which differed in random and fixed effect structure. Firstly, a model where only a binary maturation status was included as a fixed effect was run. Secondly, a model which included variables and interactions obtained during LME model (final model) selection using a continuous age at maturation variable was run. These models included either 'family' term as a random effect or both 'family' and 'individual' random effects. The later random effect structure was used for models were multiple RTL estimates were calculated and allows to account for measurement error arising due to small variation between technical replicates. We used an inverse Wishart prior for the variance component estimation. Models were run for 1000000 (models with error term) and 5000000 (models without error term) iterations discarding the first 100000 runs as burn-in in both cases, and there after sampling every 500th iteration. This allowed to obtain 1800-9800 samples from the posterior distribution. Heritability was calculated as genetic variance divided by the total variance and credible intervals for heritability estimates were given as highest posterior density intervals (HPDI).

All statistical analyses were performed in R 2.13.0 (R Core Team 2011). 
243 We did not find any main effect of experimental temperature on telomere length (likelihood ratio $(L R)$ $244=0.045, d f=202, P=0.83$ ). Likewise, a linear mixed effect model using maturation status (mature vs. 245 immature) as an explanatory variable did not reveal any significant main or interactions effects on 246 variation in telomere length (Table 1). Thus, telomere length variation among individuals was not 247 explained by their maturation status $(L R=0.021, d f=200, P=0.885)$, sex $(L R=0.208, d f=201, P=$ 248 $0.648)$, temperature $(L R=0.005, d f=199, P=0.945)$ or individual's asymptotic length $(L R=1.365, d f$ $249=203, P=0.243$; Table 1). Similarly, hatching size did not explain any variation in telomere length 250 (Table 1).

251

After restricting analysis to individuals which matured and including individual's age at maturation as a covariate, different results emerged. There was a significant interaction between an individual's sex and its age at maturation $(L R=5.818, d f=69, P=0.016$; Table 2, Fig. 1) and between age at maturation and temperature treatment $(L R=7.000, d f=69, P=0.008$; Table 2, Fig. 2). However, telomere length was not related to $\mathrm{L}_{\infty}(L R=0.033, d f=67, P=0.855$; Table 2$)$ or hatching size $(L R=$ 1.121, $d f=68, P=0.290 ;$ Table 2).

For models where a binary maturation status was used as an explanatory variable, broad sense heritability for telomere length was 0.47 (HPDI: 0.17-0.91) when measurement error was taken into account and 0.38 (HPDI: 0.12 - 0.90) when a mean of replicates was used to calculate RTL estimates. Heritability of telomere length was respectively 0.37 (HPDI: 0.09-0.91) and 0.31 (HPDI: 0.05 - 0.97) when a continuous age at maturation was included as an explanatory variable.

\section{DISCUSSION}


264 The most important finding of this study is the experimental demonstration that individual variation in

265 telomere length among sexually mature fish is influenced by rearing temperature, sex, as well as by the 266 age at which individuals matured. The effect of maturation timing on telomere length was modulated

267 by sex and temperature treatment so that telomere length in females, but not in males, decreased with 268 increasing age at maturation. Similarly, telomere length decreased with increasing age at maturation for individuals exposed to the high temperature treatment whereas not for individuals in the low temperature treatment. However, we did not find any evidence to support the expectation (cf. Geiger et al. 2012; Lee et al. 2013) that individuals with higher growth rates would have shorter telomeres). Also, we did not find that temperature treatment would have had an overall effect on telomere length. Consistent with observed environmental influences on telomere length, we also discovered that although variation in telomere length was partially influenced by genetic effects $\left(h^{2} \approx 0.31-47\right)$, much of the variation appears to be of an environmental origin. The relatively low heritability of telomere length in nine-spined sticklebacks stands in contrasts to much higher estimates from some earlier studies (Horn et al. 2011; Olsson et al. 2011; Voillemot et al. 2012; Broer et al. 2013; Reichert et al. 2015; Asghar et al. 2015; Atema et al. 2015; Becker et al. 2015).

Interactive effects between sex and age at maturation

Our initial expectation that maturation status (cf. matured $v s$ immature) would explain variation in telomere length was not supported by the data. A follow-up analysis using age at maturation as a continuous predictor and ignoring immature individuals revealed that age at maturation had a negative effect on telomere length. However, this effect was different between the two sexes. One possible explanation for this difference is that costs of maturation are sex-specific. As in many other fish species, delayed maturation in female nine-spined sticklebacks is related to a higher reproductive output (Herczeg et al. 2010; Shikano and Merilä 2011). Although we did not analyze reproductive 
287 investment in this study, increased reproductive investment is shown to be associated with shorter

288 telomeres in other fish (Gao and Munch 2015) and in birds (Bauch et al. 2013; Schultner et al.

289 2013).This may be because reproduction and particularly egg production is energetically costly, and

290 increases oxidative stress (Wang et al. 2001; Bertrand et al. 2005), which in turn accelerates telomere

291 shortening (von Zglinicki 2002). Thus, late maturing large females may be investing resources heavily

292 into egg production and have fewer resources left for self-maintenance such as, for example,

293 scavenging of reactive oxygen species which results in shorter telomeres. In contrast, since male

294 maturation (i.e. sperm production) requires substantially less energy than female maturation (Hayward

295 and Gillooly 2011), males may be left with sufficient resources for self-maintenance to avoid telomere

296 shortening.

297 Estrogen deficiency can inhibit telomerase activity (Kyo et al. 1999; Bayne et al. 2008), which is

298 normally active in all fish tissues throughout their life (Hatakeyama et al. 2008; Lund et al. 2009).

299 Similarly, estrogens may lower oxidative stress (Behl et al. 1997; Aviv 2006; Razmara et al. 2007) and

300 thereby work against telomere shorting. These considerations lead to prediction that males and late

301 maturing females should have on average shorter telomeres than early maturing females (Vihko and

302 Apter 1984; Emaus et al. 2008; Gopalakrishnan et al. 2013). This is what we indeed observed in nine-

303 spined sticklebacks in this study. Also data from medaka (Oryziaslatipes) supports this line of

304 reasoning: estrogen and telomerase activity peak at sexual maturation time in females, which is also

305 time when the greatest difference in telomere length is observed between sexes (Gopalakrishnan et al.

306 2013). This provides an alternative, but not mutually exclusive, explanation for the observation that

307 especially female telomere length is negatively related to age at maturation. 
309 Ectotherm metabolism, growth and to some extent also maturation is modulated by environmental 310 temperature (Angilletta 2009). In sticklebacks, higher temperatures increase growth and reduce 311 survival probability (Kuparinen et al. 2011; Lee et al. 2013). Temperature affects both maturation and 312 growth rate in females, while only growth rate is influenced by temperature in nine-spined stickleback 313 males (Kuparinen et al. 2011). In light of these findings, we were surprised not to find any direct association between telomere length and asymptotic length or telomere length and an overall effect of temperature treatment (Rollings et al. 2014). One possible explanation for the lack of expected associations is ad libitum feeding regime which might have provided fish with enough energy to both growth and self maintenance thereby masking an expected trade-off. This would also mean that the lack of an overall temperature effect on telomere length may not be universal across contexts and may depend on individual's ability to acquire resources. This possibly could translate into a positive correlation between life-history traits in some individuals (Hamel e al. 2009). However, alternatively and not exclusively, it may also be that individual differences in life-history strategies (e.g. relative investment to growth and reproduction) could lead to differences in telomere length which arise at certain life-history stages. In support for this expectation we observed that association between age at maturation and telomere length differed between individual in the two temperature treatments (Fig. 2).This indicates that temperature may influence telomere length through maturation rather than growth rate per se. However, much of the temperature effect appeared to be driven by the presence of early maturing males with long telomeres in the high temperature treatment, suggesting that the temperature effect is also influenced by sex. However, three-way interaction between sex, temperature and age at maturation was never significant (results not shown). 
331 Previous studies in non-model vertebrates have found that heritability of telomere length varies from

3323.8 to $99 \%$, although some of these estimates were not significantly different from zero(Horn et al.

333 2011; Olsson et al. 2011; Voillemot et al. 2012; Reichert et al. 2015; Asghar et al. 2015; Atema et al.

334 2015; Becker et al. 2015). The majority of these studies were conducted on wild or captive birds (Horn

335 et al. 2011; Voillemot et al. 2012; Reichert et al. 2015; Asghar et al. 2015; Atema et al. 2015; Becker et

336 al. 2015), and only one of them involved an ectotherm, the sand lizard (Lacertaagilis; Olsson et al.

337 2011). To the best of our knowledge, our study is the second one to report heritability of telomere

338 length for an ectothermic vertebrate, and the first one for a fish species. Our estimate $\left(h^{2} \approx 40 \%\right)$ is

339 fairly low, especially in the view that it is a broad-sense, rather than a narrow-sense estimate. Hence,

340 the true heritability is likely to be even lower than those estimated. This is because our estimate(s) may

341 include common environment and non-additive genetic contributions. Yet, the low heritability suggests

342 that environmental, rather than genetic, sources of variation are likely to explain most of the variance in

343 telomere length in fish.

344 It is tempting to speculate that the relatively low heritability of telomere length reported in this study -

345 in contrast to those of several other studies of natural vertebrate populations (Table 3 ) - might be

346 related to the fact that most other studies have been conducted in endothermic, rather than in

347 ectothermic (but see: Olsson et al., 2011) vertebrates. However, methods used for telomere length and

348 heritability estimation should be also considered (Becker et al. 2015). Many earlier estimates telomere

349 length heritability were obtained with parent-offspring regression, which assumes that the same trait is

350 measured at both generations (Lynch \& Walsh 1998). However, telomere length does not always

351 exhibit a linear relationship with age (Hatakeyama et al. 2016). Therefore measurements on parents and

352 offspring might not be comparable, leading to biased heritability estimates. Similarly, full-sib estimates

353 of heritability can be problematic since they do not control for common environment or non-additive 
genetic effects, and hence may provide upward biased estimate of heritability. However, upward-bias

355

356

357

358

cannot explain the low heritability of telomere length found in this study: if our estimates were upwardbiased, this would mean that the actual heritability of telomere length would be even lower than now estimated. With the accumulating information on estimates for heritability of telomere length across the taxa a meta-analysis would be especially rewarding and would allow to see what factors may be behind the observed discrepancies in telomere length heritability estimates. We also note that accounting for measurement error in telomere length estimates lead to change in heritability estimates, suggesting that part of the variation in heritability estimates across the studies might be explainable by differences how accurately the length of telomere lengths were estimated.

\section{Limitations of the study}

We utilized qPCR to estimate relative telomere length using the brain tissue. While qPCR has been successfully used in a large number of studies (Voillemot et al. 2012; Heidinger et al. 2012; Becker et al. 2015) and have undeniable advantages over telomere restriction fragment analysis, namely it is high-throughput (Nussey et al. 2014), concerns have been raised about possible biases caused by presence of interstitial telomericrepeats (Foote et al. 2013). This problem should not be an issue in this study because nine-spine sticklebacks are unlikely to have telomeric repeats positioned inside chromosomes (Ocalewicz et al. 2011). Further, qPCR approach may have relatively highmeasurement error if not optimized properly. Even a well-optimized assay yielding low CV's and high repeatability between technical replicates may lead to considerable measurement error. In this study we have taken this possibility into account by using two approaches to treat technical replicates and calculate heritability of telomere length. By using the two approaches we have obtained moderately low estimates of telomere heritability. 
376 Another potential concern is that we have analyzed telomere length in brain tissue. Cell turn-over in

377 neural tissue is usually lower than that in blood or liver, and since cell turn-over rate is related to

378 telomere length (Sekoguchi et al. 2007), this might have influenced the inference. If the neural tissue

379 we used had ceased its growth before sampling, then telomere lengths measured from such tissues

380 could reflect some innate differences between individuals. If so, this could indicate that late maturing

381 females and late maturing individuals in high temperature treatment had shorter telomeres because they

382 were of a lower quality, and not because the maturation or treatment had causal influence on telomere

383 length. This is not unthinkable because telomere length is indeed used as an indicator for individuals'

384 phenotypic quality and is related to early life-conditions (Aviv 2006; Heidinger et al. 2012; Bauch et al.

385 2013). Nonetheless, the use of brain tissue is unlikely to be problem in our study for several reasons.

386 First, telomere length and rate of telomere loss have been found to correlate significantly between

387 different tissue types (Hatakeyama et al. 2008; Daniali et al. 2013; Gao and Munch 2015). Second, in

388 contrast to vertebrates with determinate growth (Hastings et al. 2001), growth and neurogenesis in fish

389 continues throughout their lives (Ganz and Brand 2016). Thus, the brain is capable for plastic responses

390 to environmental influences even in adulthood (Park et al. 2012; Herczeg et al. 2015). In line with this

391 finding, telomerase is active throughout a fish life in all tissues including brain potentially facilitating

392 neural cell proliferation longer than it would be expected for mammals (Klapper et al. 1998;

393 Hatakeyama et al. 2008). Lastly, we included hatching size in the models in order to control for

394 possible initial quality related differences between individuals. While hatching size was positively

395 correlated with size at maturation $(p=0.01)$, it did not explain any variation in telomere length. Further

396 risk of initial quality differences were decreased due to random assignment of subjects across the

397 treatments. 
398 In conclusion, the results show that variation in telomere length in nine-spined sticklebacks is

399 influenced both by genetic and environmental factors, and that the latter is a greater source for the

400 observed variability. While sex, age at maturation and temperature treatment all explained significant

401 amount of variation in telomere length, their influence emerged due to interactive, rather than simple

402 isolated effects of each factor. In particular, the results indicate that timing of maturation and factors

403 influencing it may be connected to intra-specific variation in fish telomere length.

404

405

\section{ACKNOWLEDGEMENTS}

406 We would like to thank all people who helped with sampling and rearing fish, especially José M.Cano

407 and John Loehr, GáborHerczeg and AbigelGonda. Sara Rezaei is thanked for her help with DNA

408 extractions. Paolo Momigliano for linguistic corrections to an earlier version of this manuscript and

409 Zitong Li for useful comments. This study was supported by the Academy of Finland (grants: 129662,

410134728 and 218343 to JM; grants 265671 and 303685 to AK), Natural Sciences and Engineering

411 Research Council of Canada (Discovery Grant to AK), Finnish Cultural foundation (KN) and

412 Nordenskiöld samfundet (KN).

413 REFERENCES

414 Adams CE, Huntingford FA (1997) Growth, maturation and reproductive investment in Arctic charr.J

415 Fish Biol 51:750-759.doi: 10.1111/j.1095-8649.1997.tb01996.x

416 Angelier F, Vleck CM, Holberton RL, Marra PP (2013) Telomere length, non-breeding habitat and

417 return rate in male American redstarts.FunctEcol 27:342-350.doi: 10.1111/1365-2435.12041

418 Angilletta MJ (2009) Thermal Adaptation: a theoretical and empirical synthesis. OUP Oxford 
Asghar M, Bensch S, Tarka M, et al (2015) Maternal and genetic factors determine early life telomere length. Proc R Soc B BiolSci 282:20142263. doi: 10.1098/rspb.2014.2263

Atema E, Mulder E, Dugdale HL, et al (2015) Heritability of telomere length in the zebra finch. J Ornithol 156:1113-1123.doi: 10.1007/s10336-015-1212-7

Aviv A (2006) Telomeres and human somatic fitness.J Gerontol A BiolSci Med Sci 61:871-873.

Baird DM (2008) Mechanisms of telomeric instability.Cytogenet Genome Res 122:308-314.doi: $10.1159 / 000167817$

Bakaysa SL, Mucci LA, Slagboom PE,Boomsma DI, McClearn GE, Johansson B, Pedersen NL (2007) Telomere length predicts survival independent of genetic influences. Aging Cell 6:769-774. doi: $10.1111 / \mathrm{j} .1474-9726.2007 .00340 . \mathrm{x}$

Barrett ELB, Richardson DS (2011) Sex differences in telomeres and lifespan. Aging Cell 10:913-921. doi: 10.1111/j.1474-9726.2011.00741.x

Bauch C, Becker PH, Verhulst S (2013) Telomere length reflects phenotypic quality and costs of reproduction in a long-lived seabird. Proc R Soc B Biol Sci. doi: 10.1098/rspb.2012.2540

Bayne S, Jones ME, Li H, Pinto AR, Simpson ER, Liu JP (2008) Estrogen deficiency leads to telomerase inhibition, telomere shortening and reduced cell proliferation in the adrenal gland of mice. Cell Res 18:1141-1150. doi: 10.1038/cr.2008.291

Becker PJJ, Reichert S, Zahn S,Hegelbach J, Massemin S, Keller LF, Postma E, Criscuolo F (2015) Mother-offspring and nest-mate resemblance but no heritability in early-life telomere length in white-throated dippers. Proc R Soc B 282:20142924. doi: 10.1098/rspb.2014.2924 
Behl C, Skutella T, Lezoualc'h F, Post A, Widmann M, Newton CJ, HolsboerF(1997) Neuroprotection against oxidative stress by estrogens: structure-activity relationship. MolPharmacol 51:535541.doi: $10.1124 / \mathrm{mol} .51 .4 .535$

Bertrand S, Alonso-Alvarez C, Devevey G,Faivre B, Prost J, Sorci G (2005) Carotenoids modulate the trade-off between egg production and resistance to oxidative stress in zebra finches. Oecologia 147:576-584.doi: 10.1007/s00442-005-0317-8

Bischoff C, Graakjaer J, Petersen HC,HjelmborgJv, Vaupel JW, Bohr V, Koelvraa S, Christensen K (2005) The heritability of telomere length among the elderly and oldest-old. Twin Res Hum Genet 8:433-439. doi: 10.1375/twin.8.5.433

Blackburn EH (2000) Telomere states and cell fates. Nature 408:53-56.doi: 10.1038/35040500

Blasco MA (2005) Telomeres and human disease: ageing, cancer and beyond. Nat Rev Genet 6:611622. doi: $10.1038 / \operatorname{nrg} 1656$

Broer L, Codd V, Nyholt DR, Deelen J, Mangino M, Willemsen G, Albrecht E, Amin N, Beekman M, de Geus EJ, Henders A, Nelson CP, Steves CJ, Wright MJ, de Craen AJ, Isaacs A, Matthews M, Moayyeri A, Montgomery GW, Oostra BA, Vink JM, Spector TD, Slagboom PE, Martin NG, Samani NJ, van Duijn CM, Boomsma DI(2013) Meta-analysis of telomere length in 19713 subjects reveals high heritability, stronger maternal inheritance and a paternal age effect. Eur J Hum Genet 21:1163-1168.doi: 10.1038/ejhg.2012.303

Campisi J (2005) Senescent cells, tumor suppression, and organismal aging: good citizens, bad neighbors. Cell 120:513-522. doi: 10.1016/j.cell.2005.02.003

Cawthon RM (2002) Telomere measurement by quantitative PCR.Nucleic Acids Res 30:e47. 
460

461

462

463

464

465

466

467

468

469

470

471

472

473

474

475

476

477

478

479

Daniali L, Benetos A, Susser E, Kark JD, Labat C, Kimura M, Desai K, Granick M, Aviv A(2013) Telomeres shorten at equivalent rates in somatic tissues of adults. Nat Commun 4:1597. doi: $10.1038 /$ ncomms 2602

DormannCF, Elith J, Bacher S, Buchmann C, Carl G, Carré G, Marquéz JRG, Gruber B, Lafourcade B, Leitão PJ, Münkemüller T, McClean C, Osborne PE, Reineking B, Schröder B, Skidmore AK, Zurell D, Lautenbach S (2013)Collinearity: a review of methods to deal with it and a simulation study evaluating their performance. Ecography 36:27-46.doi: 10.1111/j.16000587.2012.07348.x

Emaus A, Espetvedt S, Veierød MB, Ballard-Barbash R, Furberg AS, Ellison PT, Jasienska G, Hjartåker A, Thune I(2008) 17-beta-estradiol in relation to age at menarche and adult obesity in premenopausal women. Hum ReprodOxfEngl 23:919-927. doi: 10.1093/humrep/dem432

Epel ES, Blackburn EH, Lin J, Dhabhar FS, Adler NE, Morrow JD, Cawthon RM(2004) Accelerated telomere shortening in response to life stress. ProcNatlAcadSci U S A 101:17312-17315.doi: 10.1073/pnas.0407162101

Foote CG, Daunt F, González-Solís J, Nasir L, Phillips RA, Monaghan P (2010) Individual state and survival prospects: age, sex, and telomere length in a long-lived seabird. BehavEcol arq178.doi: 10.1093/beheco/arq178

Foote CG, Vleck D, Vleck CM (2013) Extent and variability of interstitial telomeric sequences and their effects on estimates of telomere length. MolEcolResour 13:417-428. doi: 10.1111/17550998.12079 
480

481

482

483

484

485

486

487

488

489

490

491

492

493

494

495

496

497

498

499

500

Ganz J, Brand M (2016) Adult neurogenesis in fish. Cold Spring HarbPerspectBiol a019018.doi: 10.1101/cshperspect.a019018

Gao J, Munch SB (2015) Does reproductive investment decrease telomere length in Menidiamenidia? PLOS ONE 10:e0125674.doi: 10.1371/journal.pone.0125674

Geiger S, Le Vaillant M, Lebard T, Reichert S, Stier A, LE Maho Y, Criscuolo F(2012) Catching-up but telomere loss: half-opening the black box of growth and ageing trade-off in wild king penguin chicks. MolEcol 21:1500-1510.doi: 10.1111/j.1365-294X.2011.05331.x

Gopalakrishnan S, Cheung NK, Yip BW, Au DW (2013) Medaka fish exhibits longevity gender gap, a natural drop in estrogen and telomere shortening during aging: a unique model for studying sexdependent longevity. Front Zool 10:78. doi: 10.1186/1742-9994-10-78

Hadfield JD (2010) MCMC Methods for Multi-Response Generalized Linear Mixed Models: The MCMCglmm R Package. Journal of Statistical Software, 33: 1-22.

Hamel S, Côté SD, Gaillard JM, Festa-BianchetM(2009) Individual variation in reproductive costs of reproduction: high-quality females always do better. J AnimEcol, 78: 143151.doi:10.1111/j.1365-2656.2008.01459.x

Hastings NB, Tanapat P, Gould E (2001) Neurogenesis in the adult mammalian brain. ClinNeurosci Res 1:175-182.doi: 10.1016/S1566-2772(01)00003-2

Hatakeyama H, Nakamura K-I, Izumiyama-Shimomura N, Ishii A, Tsuchida S, Takubo K, Ishikawa N(2008) The teleost Oryziaslatipes shows telomere shortening with age despite considerable telomerase activity throughout life. Mech Ageing Dev 129:550-557.doi:

10.1016/j.mad.2008.05.006 
501 Hatakeyama H, Yamazaki H, Nakamura K-I, Izumiyama-Shimomura N, Aida J, Suzuki H, Tsuchida S,

502 Matsuura M, Takubo K, Ishikawa N(2016) Telomere attrition and restoration in the normal 503 teleost Oryziaslatipes are linked to growth rate and telomerase activity at each life stage. Aging $504 \quad 8: 62-75$.

505 Hayward A, Gillooly JF (2011) The cost of sex: quantifying energetic investment in gamete production 506 by males and females. PLOS ONE 6:e16557.doi: 10.1371/journal.pone.0016557

507

508

509

510

511

512

513

514

515

516

517

518

519

520

Heidinger BJ, Blount JD, Boner W, Griffiths K, Metcalfe NB, Monaghan P(2012) Telomere length in early life predicts lifespan. ProcNatlAcadSci U S A 109:1743-1748. doi: 10.1073/pnas.1113306109

Herczeg G, Gonda A, Balázs G, Noreikiene K, Merilä J(2015) Experimental evidence for sex-specific plasticity in adult brain. Front Zool. doi: 10.1186/s12983-015-0130-0

Herczeg G, Gonda A, Merilä J (2010) Rensch’s rule inverted - female-driven gigantism in nine-spined stickleback Pungitius pungitius.J AnimEcol 79:581-588.doi: 10.1111/j.13652656.2010.01665.x

Horn T, Robertson BC, Will M, Eason DK, Elliott GP, Gemmell NJ(2011) Inheritance of telomere length in a bird. PLoS ONE 6:e17199.doi: 10.1371/journal.pone.0017199

Houle D (1992) Comparing evolvability and variability of quantitative traits. Genetics 130:195-204.

Kappei D, Londoño-Vallejo JA (2008) Telomere length inheritance and aging. Mech Ageing Dev 129:17-26.doi: 10.1016/j.mad.2007.10.009

Kirkwood TBL (1977) Evolution of ageing.Nature 270:301-304.doi: 10.1038/270301a0 
521 Kirkwood TBL, Rose MR (1991) Evolution of senescence: late survival sacrificed for reproduction.

522 Philos Trans R Soc B BiolSci 332:15-24.doi: 10.1098/rstb.1991.0028

523 Klapper W, Heidorn K, Kühne K, Parwaresch R, Krupp G(1998) Telomerase activity in "immortal"

524 fish. FEBS Lett 434:409-412.doi: 10.1016/S0014-5793(98)01020-5

525 Kuparinen A, Cano JM, Loehr J,Herczeg G, Gonda A, Merilä J (2011) Fish age at maturation is 526

527

528

529

530

531

532

533

534

535

536

537

538

539

Kyo S, Takakura M, Kanaya T, Zhuo W, Fujimoto K, Nishio Y, Orimo A, Inoue M(1999) Estrogen activates telomerase. Cancer Res 59:5917-5921.

Lee W-S, Monaghan P, Metcalfe NB (2013) Experimental demonstration of the growth rate-lifespan trade-off. Proc R Soc B 280:20122370. doi: 10.1098/rspb.2012.2370

Lund TC, Glass TJ, Tolar J, Blazar BR (2009) Expression of telomerase and telomere length are unaffected by either age or limb regeneration in Daniorerio. PLoS ONE. doi: 10.1371/journal.pone.0007688

Merilä J, Sheldon BC (1999) Genetic architecture of fitness and nonfitness traits: empirical patterns and development of ideas. Heredity 83:103-109.doi: 10.1046/j.1365-2540.1999.00585.x

Mizutani Y, Tomita N, Niizuma Y, Yoda K (2013) Environmental perturbations influence telomere dynamics in long-lived birds in their natural habitat. BiolLett 9:20130511. doi:

$10.1098 / \mathrm{rsbl} .2013 .0511$ 
540 Monaghan P (2010) Telomeres and life histories: the long and the short of it. Ann N Y AcadSci 541 1206:130-142. doi: 10.1111/j.1749-6632.2010.05705.x

542 Monaghan P, Haussmann MF (2006) Do telomere dynamics link lifestyle and lifespan? Trends $543 \quad$ EcolEvol 21:47-53.doi: 10.1016/j.tree.2005.11.007

544 Nussey DH, Baird D, Barrett E, Boner W, Fairlie J, Gemmell N, Hartmann N, Horn T, Haussmann M, 545 Olsson M, Turbill C, Verhulst S, Zahn S, Monaghan P(2014) Measuring telomere length and 546 telomere dynamics in evolutionary biology and ecology. Methods EcolEvol 5:299-310.doi:

547 10.1111/2041-210X.12161

548

549

550

551

552

553

554

555

556

557

558

559

Ocalewicz K, Woznicki P, Furgala-Selezniow G, Jankun M (2011) Chromosomal location of Ag/CMA3-NORs, 5S rDNA and telomeric repeats in two stickleback species. Ital J Zool 78:1219.doi: $10.1080 / 11250003.2010 .532160$

Olsson M, Pauliny A, Wapstra E, Uller T, Schwartz T, Blomqvist D(2011) Sex differences in sand lizard telomere inheritance: paternal epigenetic effects increases telomere heritability and offspring survival. PLoS ONE 6:e17473.doi: 10.1371/journal.pone.0017473

Park PJ, Chase I, Bell MA (2012) Phenotypic plasticity of the threespine stickleback Gasterosteus aculeatus telencephalon in response to experience in captivity. CurrZool 58:189-210.doi: $10.1093 /$ czoolo/58.1.189

Peterson DR, Mok HOL, Au DWT (2015) Modulation of telomerase activity in fish muscle by biological and environmental factors. Comp BiochemPhysiol Part C ToxicolPharmacol 178:5159. doi: 10.1016/j.cbpc.2015.09.004 
560 Plot V, Criscuolo F, Zahn S, Georges J-Y (2012) Telomeres, age and reproduction in a long-lived $561 \quad$ reptile. PLoS ONE 7:e40855.doi: 10.1371/journal.pone.0040855

562 Price T, Schluter D (1991) On the low heritability of life-history traits. Evolution 45:853-861.doi:

563 $10.2307 / 2409693$

564 R Development Core Team (2011) R: A language and environment for statistical computing. R 565 Foundation for Statistical Computing, Vienna, Austria. ISBN 3-900051- 07-0

566 Ramakers C, Ruijter JM, Deprez RHL, Moorman AFM (2003) Assumption-free analysis of 567 quantitative real-time polymerase chain reaction (PCR) data. NeurosciLett 339:62-66.

568

569

570

Razmara A, Duckles SP, Krause DN, Procaccio V (2007) Estrogen suppresses brain mitochondrial oxidative stress in female and male rats. Brain Res 1176:71-81. doi:10.1016/j.brainres.2007.08.036

571

572 inheritance in the king penguin. Heredity 114:10-16.doi: 10.1038/hdy.2014.60

573

Rice WR (1984) Sex chromosomes and the evolution of sexual dimorphism.Evolution 38:735-742.doi:

574 $10.2307 / 2408385$

575 Roff DA (1993) Evolution of life histories: theory and analysis. Springer

576 Rohlf FJ (2002) tpsDIG, digitize landmarks and outlines. Department of Ecology and Evolution, State 577 University of New York, Stony Brook, NY 
578 Rollings N, Miller E, Olsson M (2014) Telomeric attrition with age and temperature in Eastern 579 mosquitofish (Gambusiaholbrooki). Naturwissenschaften 101:241-244.doi: 10.1007/s00114$580 \quad 014-1142-x$

581 Schultner J, Kitaysky AS, Gabrielsen GW, Hatch SA, Bech C (2013) Differential reproductive 582 responses to stress reveal the role of life-history strategies within a species. Proc R Soc B 583 BiolSci 280:20132090. doi: 10.1098/rspb.2013.2090

584 585

586

587

588

589

590

591

592

593

594

595

596

Sekoguchi S, Nakajima T, Moriguchi M, Jo M, Nishikawa T, Katagishi T, Kimura H, Minami M, Itoh Y, Kagawa K, Tani Y, OkanoueT (2007) Role of cell-cycle turnover and oxidative stress in telomere shortening and cellular senescence in patients with chronic hepatitis C. J GastroenterolHepatol 22:182-190. doi: 10.1111/j.1440-1746.2006.04454.x

Shikano T, Merilä J (2011) Body size and the number of vertebrae in the nine-spined stickleback (Pungitius pungitius). Biol J Linn Soc 104:378-385.doi: 10.1111/j.1095-8312.2011.01731.x

Shimada Y, Shikano T, Kuparinen A, Gonda A, Leinonen T, Merilä J(2011) Quantitative genetics of body size and timing of maturation in two nine-spined stickleback (Pungitius pungitius) populations. PLOS ONE 6:e28859.doi: 10.1371/journal.pone.0028859

Slatkin M (1984) Ecological causes of sexual dimorphism. Evolution 38:622-630.doi: $10.2307 / 2408711$

Untergasser A, Cutcutache I, Koressaar T, Ye J, Faircloth BC, Remm M, Rozen SG (2012) Primer3-new capabilities and interfaces. Nucleic Acids Res 40:e115.doi: 10.1093/nar/gks596 
597 Uusi-Heikkilä S, Kuparinen A, Wolter C,Meinelt T, Arlinghaus R (2011) Paternal body size affects 598 reproductive success in laboratory-held zebrafish (Daniorerio). Environ Biol Fishes 93:461599 474. doi: $10.1007 /$ s10641-011-9937-5

600 Vihko R, Apter D (1984) Endocrine characteristics of adolescent menstrual cycles: impact of early 601 menarche. J Steroid Biochem 20:231-236.doi: 10.1016/0022-4731(84)90209-7

602

603

604

605

606

607

608

609

610

611

612

Voillemot M, Hine K, Zahn S,Criscuolo F, Gustafsson L, Doligez B, Bize P (2012) Effects of brood size manipulation and common origin on phenotype and telomere length in nestling collared flycatchers. BMC Ecol 12:17.doi: 10.1186/1472-6785-12-17

vonBertalanffy L (1938) A quantitative theory of organic growth (inquiries on growth laws. II). Hum Biol 10:181-213.

vonZglinicki T (2002) Oxidative stress shortens telomeres. Trends BiochemSci 27:339-344. doi: 10.1016/S0968-0004(02)02110-2

Wang Y, Salmon AB, Harshman LG (2001) A cost of reproduction: oxidative stress susceptibility is associated with increased egg production in Drosophila melanogaster. ExpGerontol 36:13491359.doi: 10.1016/S0531-5565(01)00095-X 
613 Table 1. Linear mixed effect (LME) model selection for variables explaining variation in relative 614 telomere length where a binary maturation status variable was included in the model.

\begin{tabular}{lccc}
\hline $\begin{array}{l}\text { Explanatory } \\
\text { variable }^{\mathbf{a}}\end{array}$ & $\begin{array}{c}\text { Parameter estimate } \\
\pm \text { SE }\end{array}$ & $\boldsymbol{d f}$ & $\begin{array}{c}\text { Likelihood ratio } \\
(\boldsymbol{P})^{\mathbf{b}}\end{array}$ \\
\hline Intercept & $0.061 \pm 0.064$ & 204 & \\
$\mathrm{~L}_{\infty}$ & $0.004 \pm 0.004$ & 203 & $1.365(0.243)$ \\
Hatching size & $0.070 \pm 0.128$ & 202 & $0.299(0.585)$ \\
Sex (male) & $-0.022 \pm 0.049$ & 201 & $0.208(0.648)$ \\
Maturation status & $-0.008 \pm 0.058$ & 200 & $0.021(0.885)$ \\
$(\mathrm{M} ;$ ) & & & \\
Temperature (T; & $0.003 \pm 0.047$ & 199 & $0.005(0.945)$ \\
$\left.17^{\circ} \mathrm{C}\right)$ & $-0.006 \pm 0.007$ & 198 & $0.603(0.437)$ \\
$\mathrm{M} \times \mathrm{L} \infty$ & $-0.112 \pm 0.110$ & 197 & $1.057(0.304)$ \\
$\mathrm{Sex} \times \mathrm{M}$ & $0.006 \pm 0.007$ & 196 & $0.782(0.377)$ \\
$\mathrm{L} \infty \mathrm{T}$ & $0.059 \pm 0.098$ & 195 & $0.374(0.541)$ \\
$\mathrm{Sex} \times \mathrm{T}$ & $-0.002 \pm 0.009$ & 194 & $0.082(0.774)$ \\
$\mathrm{Sex} \times \mathrm{L}_{\infty}$ & $0.009 \pm 0.101$ & 193 & $0.009(0.925)$ \\
$\mathrm{M} \times \mathrm{T}$ & & & \\
\hline
\end{tabular}

615

616

617

618

619 Abbreviations: $\mathrm{L}_{\infty}$-asymptotic length, SE-standard error, $d f$ - degrees of freedom.

${ }^{\mathrm{a}} \mathrm{Sex}=$ female, $\mathrm{TEMP}=14^{\circ} \mathrm{C}, \mathrm{MAT}=0$ (immature) are included in the intercept and considered as references 
620 Table 2 Final model (in bold) and linear mixed effect (LME) model selection for variables explaining 621 relative telomere length. A continuous age at maturation variable was included in the model.

\begin{tabular}{|c|c|c|c|}
\hline Explanatory variable $^{\mathbf{a}}$ & $\begin{array}{c}\text { Parameter estimate } \\
\pm \mathrm{SE}\end{array}$ & $d f$ & $\begin{array}{l}\text { Likelihood ratio } \\
(P)^{b}\end{array}$ \\
\hline Intercept & $0.795 \pm 0.666$ & 69 & \\
\hline Sex (male) & $-1.743 \pm 0.667$ & 69 & $9.328(0.009)$ \\
\hline $\begin{array}{l}\text { Age at maturation } \\
(\mathrm{AM})\end{array}$ & $-0.006 \pm 0.006$ & 69 & $11.950(0.008)$ \\
\hline $\begin{array}{l}\text { Temperaturetreatment } \\
\left(\mathrm{T} ; 17^{\circ} \mathrm{C}\right)\end{array}$ & $1.360 \pm 0.557$ & 69 & $7.819(0.020)$ \\
\hline $\operatorname{Sex} \times \mathbf{A M}$ & $0.015 \pm 0.006$ & 69 & $5.818(0.016)$ \\
\hline $\mathbf{A M} \times \mathbf{T}$ & $-0.014 \pm 0.005$ & 69 & $7.000(0.008)$ \\
\hline Hatching size & $0.215 \pm 0.212$ & 68 & $1.121(0.290)$ \\
\hline $\mathrm{L}_{\infty}$ & $-0.001 \pm 0.007$ & 67 & $0.0334(0.855)$ \\
\hline $\mathrm{AM} \times \mathrm{L}_{\infty}$ & $0.001 \pm 0.000$ & 66 & $2.0416(0.153)$ \\
\hline $\operatorname{Sex} \times \mathrm{L}_{\infty}$ & $0.027 \pm 0.019$ & 65 & $2.483(0.115)$ \\
\hline $\mathrm{L}_{\infty} \times \mathrm{T}$ & $0.006 \pm 0.012$ & 64 & $0.241(0.624)$ \\
\hline $\operatorname{Sex} \times \mathrm{T}$ & $-0.072 \pm 0.233$ & 63 & $0.111(0.740)$ \\
\hline
\end{tabular}

622

623

Abbreviations: $\mathrm{L}_{\infty}-$, asymptotic length, SE-standard error, df-degrees of freedom

624

${ }^{\mathrm{a}} \mathrm{Sex}=$ female and $\mathrm{TEMP}=14^{\circ} \mathrm{C}$ are included in the intercept and considered as a references

625

${ }^{\mathrm{b}}$ Likelihood ratio tests were conducted and p-values obtained by comparing models with and without the given

626 term

627

628 
629 Table 3 Synopsis of the published heritability estimates of telomere length from non-model organisms

\begin{tabular}{|c|c|c|c|c|c|c|c|}
\hline Taxon & Species & $\begin{array}{l}h^{2} \\
(\mathrm{SE} / \mathrm{CI})\end{array}$ & $\begin{array}{l}\text { Method for } \\
h^{2} \text { estimation }\end{array}$ & $\begin{array}{l}\text { Telomere } \\
\text { measure } \\
\text { (method) }\end{array}$ & $\mathrm{n}_{\text {families }}$ & $\mathrm{n}_{\text {individuals }}$ & Reference \\
\hline Teleostei & $\begin{array}{l}\text { Nine-spined stickleback } \\
\text { (Pungitius pungitius) }\end{array}$ & $\begin{array}{l}0.47 \\
(0.17- \\
0.91) \\
0.37 \\
(0.09- \\
0.91) \\
0.38 \\
(0.12- \\
0.90) \\
0.31 \\
(0.05- \\
0.97)\end{array}$ & FS (Anim) & $\begin{array}{l}\text { RTL } \\
\text { (qPCR) }\end{array}$ & 9 & $83 ; 213$ & $\begin{array}{l}\text { current } \\
\text { study }\end{array}$ \\
\hline Reptilia & Sand lizard (Lacertaagilis) & $\begin{array}{l}0.52 \\
1.23\end{array}$ & $\mathrm{PO}$ & $\begin{array}{l}\text { Average } \\
\text { TL } \\
(\mathrm{TRF})\end{array}$ & $\begin{array}{l}40 \\
\text { (daughter- } \\
\text { dam) } \\
80 \text { (son- } \\
\text { sire) }\end{array}$ & $\begin{array}{l}80 \\
110{ }_{0}^{\lambda}\end{array}$ & $\begin{array}{l}\text { (Olsson et } \\
\text { al. 2011) }\end{array}$ \\
\hline \multirow[t]{6}{*}{ Aves } & $\begin{array}{l}\text { Kakapo } \\
\text { (Strigopshabroptilus) }\end{array}$ & 0.84 & $\mathrm{PO}$ & $\begin{array}{l}\text { Average } \\
\text { TL } \\
(\mathrm{TRF})\end{array}$ & 29 & $\begin{array}{l}29 \\
\text { offspring } \\
29 \\
\text { mothers }\end{array}$ & $\begin{array}{l}\text { (Horn et } \\
\text { al. 2011) }\end{array}$ \\
\hline & $\begin{array}{l}\text { Collared flycatcher } \\
\text { (Ficedulaalbicollis) }\end{array}$ & $\begin{array}{l}0.09 \\
0.18^{*}\end{array}$ & FS & $\begin{array}{l}\text { RTL } \\
(\mathrm{qPCR})\end{array}$ & 74 & 359 & $\begin{array}{l}\text { (Voillemot } \\
\text { et al. } \\
2012 \text { ) }\end{array}$ \\
\hline & $\begin{array}{l}\text { White-throated dippers } \\
\text { (Cincluscinclus) }\end{array}$ & $\begin{array}{l}0.038 \\
(0.069)\end{array}$ & Anim & $\begin{array}{l}\text { RTL } \\
\text { (qPCR) }\end{array}$ & NA & 177 & $\begin{array}{l}\text { (Becker et } \\
\text { al. 2015) }\end{array}$ \\
\hline & $\begin{array}{l}\text { Great reed warbler } \\
\text { (Acrocephalusarundinaceus) }\end{array}$ & $\begin{array}{l}0.35 \\
(0.07) \\
0.48 \\
(0.12)\end{array}$ & Anim & $\begin{array}{l}\text { RTL } \\
\text { (qPCR) }\end{array}$ & 46 & 193 & $\begin{array}{l}\text { (Asghar et } \\
\text { al. 2015) }\end{array}$ \\
\hline & $\begin{array}{l}\text { King penguin } \\
\text { (Aptenodytespatagonicus) }\end{array}$ & $\begin{array}{l}0.2 \\
(0.1) \\
0.3 \\
(0.1)\end{array}$ & $\mathrm{PO}$ & $\begin{array}{l}\text { RTL } \\
(\mathrm{qPCR})\end{array}$ & 53 & $\begin{array}{l}53 \\
\text { offspring } \\
106 \\
\text { parents }\end{array}$ & $\begin{array}{l}\text { (Reichert } \\
\text { et al. } \\
2015 \text { ) }\end{array}$ \\
\hline & $\begin{array}{l}\text { Zebra finch } \\
\text { (Taeniopygiaguttata) }\end{array}$ & $\begin{array}{l}0.99 \\
(0.87- \\
1)\end{array}$ & Anim & $\begin{array}{l}\text { Average } \\
\text { TL } \\
\text { (TRF) }\end{array}$ & 73 & 125 & $\begin{array}{l}\text { (Atema et } \\
\text { al. 2015) }\end{array}$ \\
\hline
\end{tabular}


631 Anim = animal model, FS = full-sib analysis; $\mathrm{PO}=$ parent offspring regression; $\mathrm{TRF}=$ telomere

632 restriction fragment analysis; $\mathrm{qPCR}=$ quantitative $\mathrm{PCR}$ analysis; $\mathrm{RTL}=$ relative telomere length; $\mathrm{TL}=$ 633 telomere length; $\mathrm{SE}=$ standard error; $\mathrm{CI}=$ confidence interval. 


\section{Figure legends}

636 Fig. 1 Relative telomere length (RTL) as a function of age at maturation in male and female nine637 spined sticklebacks. RTL decreases with postponed maturation in female sticklebacks (f, open circles, 638 dashed line), while males show little response in RTL with maturation schedule (m, black dots, solid 639 line)

640

641 Fig. 2 Relative telomere length (RTL) as a function of age at maturation in high $\left(17^{\circ} \mathrm{C}\right.$, open circles, 642 dashed line $)$ and low $\left(14^{\circ} \mathrm{C}\right.$, black dots, solid line $)$ temperature treatments in nine-spined sticklebacks

643

644 Fig. 3 Mean and variation in residual relative telomere length (RTL) between nine-spined stickleback 645 families (F4 to F12) included into the study. In the box plot, 25 to 75 percentiles of the data are 646 enclosed by the box and a median is marked with a horizontal line. Whiskers show range of the data 
Fig. 1

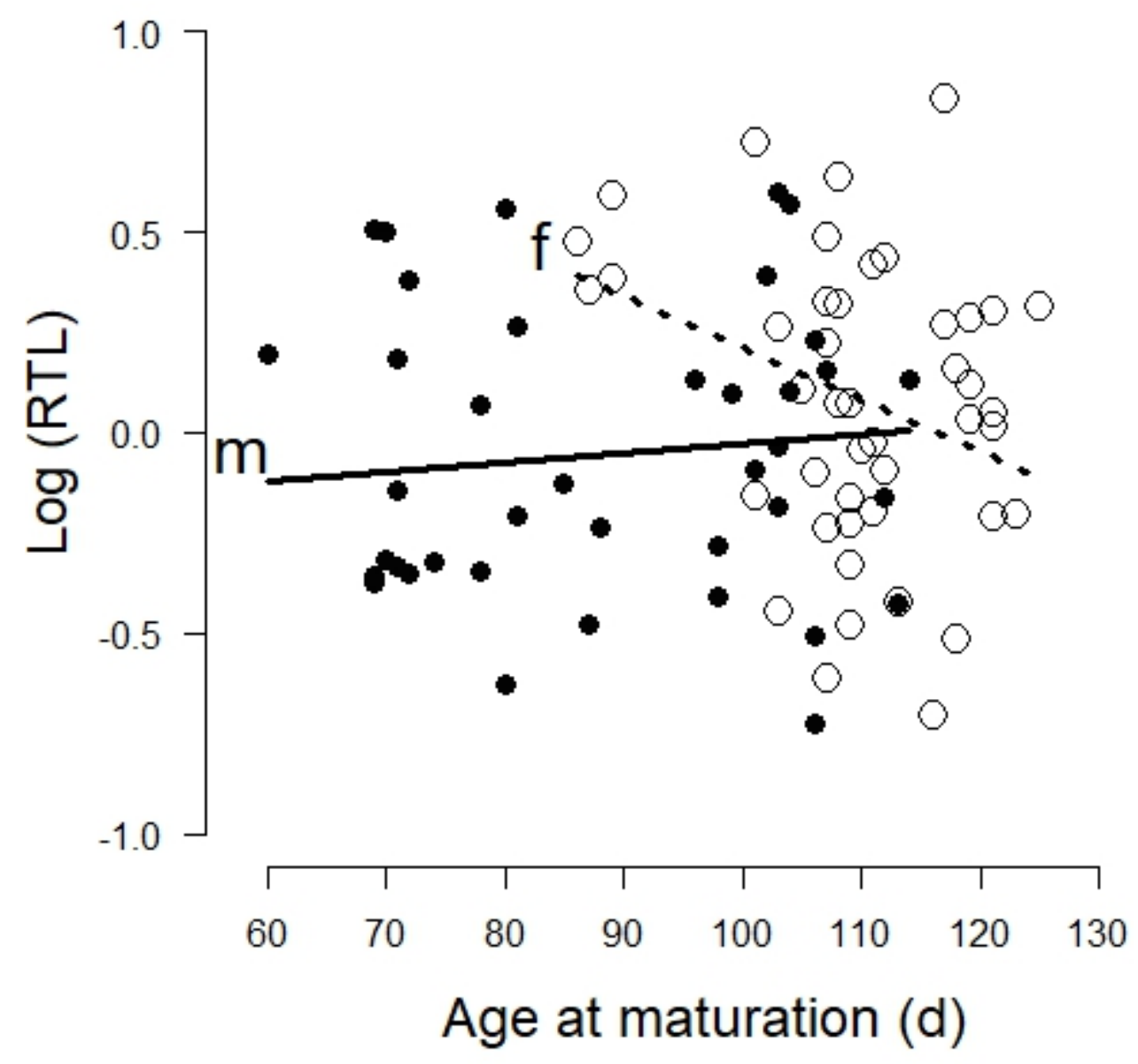


Fig. 2

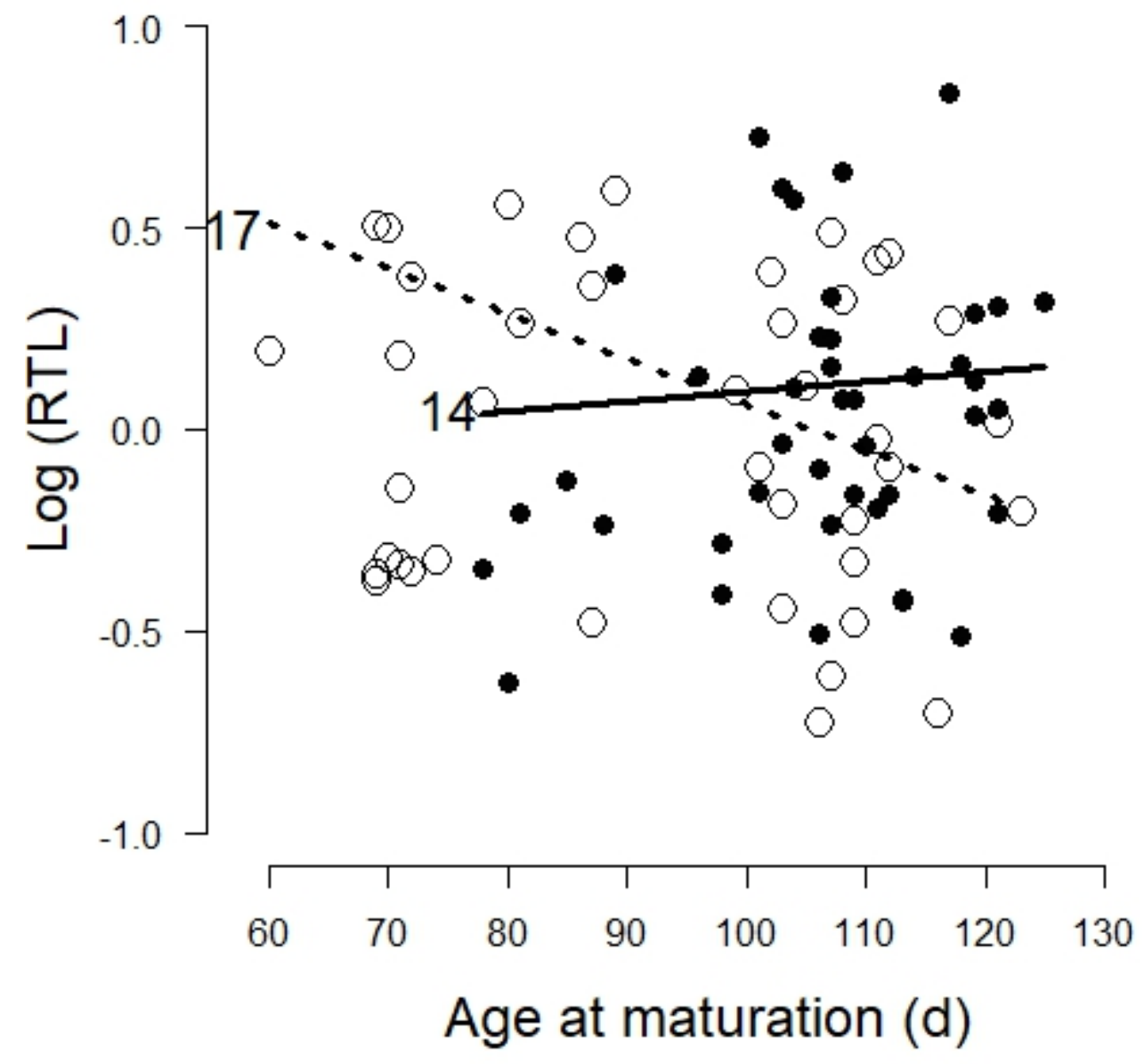


Fig. 3

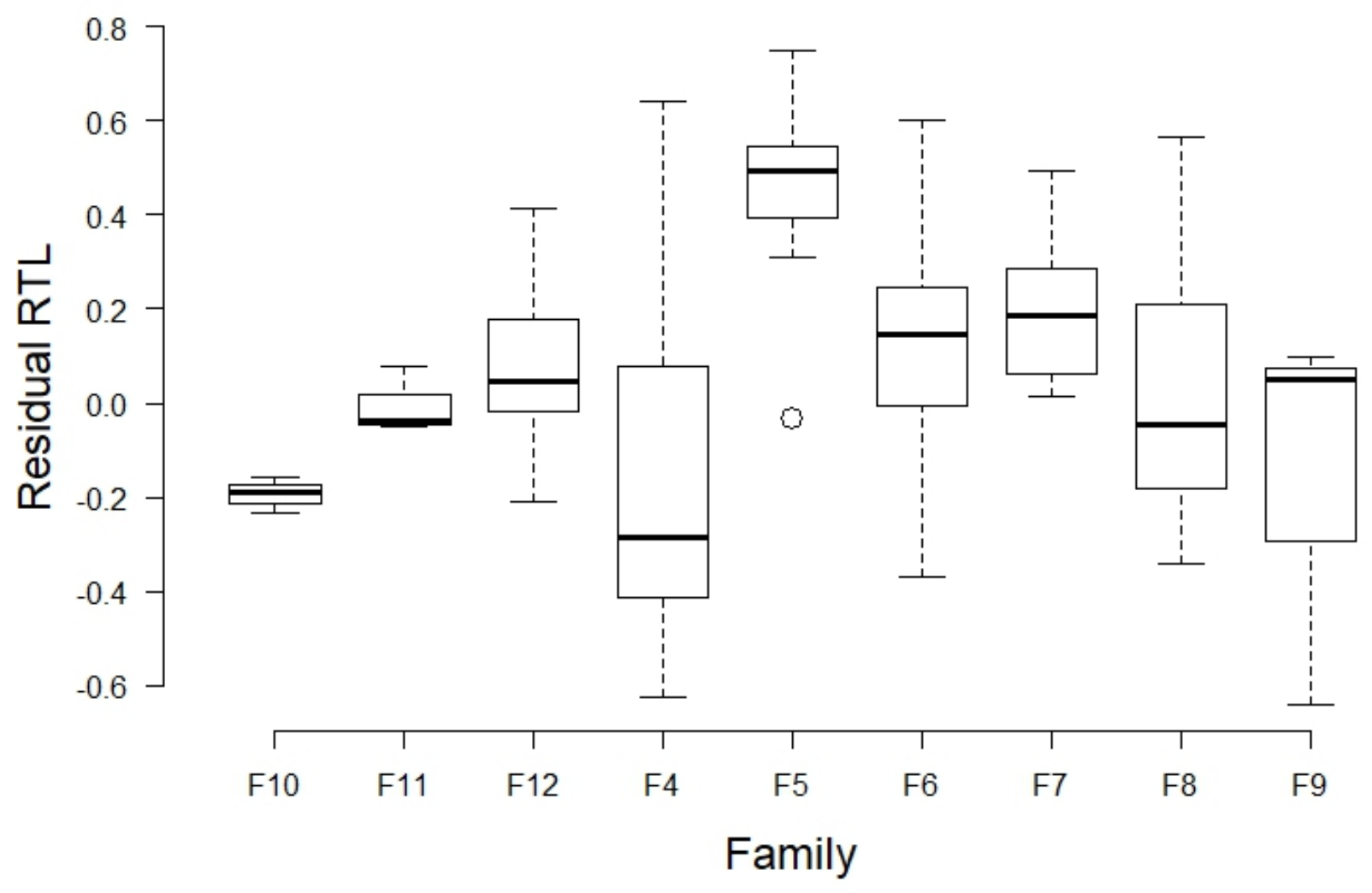

